\title{
Production of Neural Progenitors from Bone Marrow Mesenchymal Stem Cells
}

\author{
Maeda Mohammad1*, Nahi Yaseen', Ahmad Al-Joubory², Rafal Abdullah', Noah Mahmood1, \\ Aesar A. Ahmed ${ }^{1}$, Ahmed Al-Shammari ${ }^{*}$ \\ ${ }^{1}$ Experimental Therapy Department, Iraqi Center of Cancer and Medical Genetic Research, Al-Mustansiriyah \\ University, Baghdad, Iraq \\ ${ }^{2}$ Neuroscience Hospital, Baghdad, Iraq \\ Email: "maeda.mohammad@iccmgr.org, "ahmed.alshammari@iccmgr.org
}

Received 1 August 2015; accepted 25 December 2015; published 29 December 2015

Copyright (C) 2016 by authors and Scientific Research Publishing Inc.

This work is licensed under the Creative Commons Attribution International License (CC BY).

http://creativecommons.org/licenses/by/4.0/

c) (i) Open Access

\section{Abstract}

In the brain, there are hundreds of types of specialized neurons and to generate one type of them we need to have neural progenitors for differentiation to specific neuron type. Mesenchymal stem cells (MSCs) are easily isolated, cultured, manipulated ex vivo, showing great potential for therapeutic applications. The adult MSCs have the potential to produce progeny that differentiate into a variety of cell types such as neurons. This fact suggests that MSCs derived neurons are an important cell type and a deep understanding of the molecular characteristics of it would significantly enhance the advancement of cell therapy for neurological disorders. Therefore, in this study, we isolated, identified, and studied neural progenitors by measuring expression levels through neurogenesis pathway of three neural differentiation markers nestin (NES), neurofilament (NF-L), and microtubule association protein (MAP-2) from mouse bone marrow MSCs (mouse bmMSCs) by using butylated hydroxyanisole (BHA) and diethyl sulfoxide (DMSO) as neural inducers agents. The results of immunocytochemistry and Real Time-PCR showed that in contrast to MSCs, neural differentiated cells showed neural progenitor pattern by showing stable increase in NES gene expression through differentiation process with increasing the protein expression through different exposures times, while NF-L gene and protein expression start to increased after $48 \mathrm{~h}$ but not replaced the NES expression completely even when its expression passed NES levels. The maturation marker Map-2 expression was low during the duration of differentiation period in protein and gene expression, which prove that these cells are still progenitors and can be redirected into specific type of neurons by further treatments.

\footnotetext{
${ }^{*}$ Corresponding authors.
} 


\section{Keywords}

\section{BHA, Nestin, Neural Progenitors Cells, MSCs, MAP-2}

\section{Introduction}

Mesenchymal stromal cells or MSCs are a type of widely distributed adult stem cell in connective tissues [1] [2]. They were easy to isolate and propagate and possess the ability to differentiate into many different cell lineages, including osteoblasts, chondrocytes, adipocytes, hepatocytes, and neuron-like cells since the nineteenth of the past century [3]-[6]. With these properties, MSCs have been widely applied in regenerative medicine research and experimental cell therapy for a wide range of disorders such parkinson's disease (PD) [7], huntington's disease [8], amyotrophic lateral sclerosis (ALS) [9], and alzheimer's disease (AD) [10].

Mesenchymal stem cells are induced to differentiate into neural cells under the appropriate differentiation media by several researches [11]-[14]. The neural development of MSCs could provide a source to treat specific neurological deficits because the central nervous system (CNS) has limited capacity for self-repair and the loss of its cells generally results in permanent tissue damage [15]-[17].

There have been several studies showing that sulfhydryl groups (-SH) in compounds such as $\beta$-mercaptoethanol (BME), BHA, DMSO, cysteine, and glutathione (GSH) are essential for neural induction of bone marrow MSCs [18]-[21]. Exposure of MSCs to agents such as BHA, induces neural morphological features along with the expression of neural-specific genes such as NEFL, TUBB3 ( $\beta$ III-tubulin), and neuron-specific enolase (NSE). In addition, protein expression levels of nestin, $\beta$ III-tubulin, and tyrosine hydroxylase remarkably increased in differentiated MSCs [22].

The intermediate filament protein (IMF) which is the major stricture of cytoskeletons is classified into several types, which expressed mostly in nerve cells and brain, such as NES as a type IV which are implicated in the radial growth of the axon, the nestin-expressing cells are found frequently (though not necessarily exclusively) in areas of regeneration, where they might function as a reservoir of stem/progenitor cells capable of proliferation and differentiation [23]. Neurofilaments (such as NF-L) are another type of IMF group, which expressed predominantly in axonal neurons, peripherin by a subset of neurons [24], also expressed during neurogenesis process, and play as a biomarker for axonal injury, because of his higher expression in axon [25]. Another neural marker was MAP-2 that belongs to the microtubule-associated protein family which involved in microtubule assembly, which is an essential step in neuritogenesis and serves to stabilize microtubules growth by cross linking with intermediate filaments. It expressed in mature neurons such as dendrite cells and perikarya cells, and transiently expressed in axonal neurites during early neural cytogenesis [26] [27].

The objective of this study was to produce neural progenitor cells from MSCs that can be directed later to produce specific neuron type for cellular therapy of the nervous system.

\section{Materials and Methods}

This study was carried out on the Iraqi center of cancer and medical genetic research (ICCMGR)/experimental therapy department between 2012-2014.

\subsection{Isolation of MSCs from Mouse Bone Marrow}

The bone marrow culture was prepared as described by Freshney [28] by Killing the donor male Swiss Albino mice by cervical dislocation ( 3 - 6 weeks old, provided by ICCMGR animal house unite, all the work approved by the ICCMGR animal care and use committee). Under sterilize conditions, the fur washed with $70 \%$ alcohol femurs and tibias were removed and both collected in a petri dish containing transport media MEM (Minimum Essential medium) (US Biological, Massachusetts USA) supplemented with five fold antibiotics streptomycin (Cox Pharmaceutical CO., LTD, UK) and ampicillin (Kontam Pharmaceuticals CO., LTD, China) as $500 \mathrm{mg} / \mathrm{ml}$. In the laboratory and under sterilize conditions, the femurs and tibias were clean off from remaining muscle tissues with sterile surgical tools and washed few time with normal saline solution phosphate buffer saline (PBS), holed the femur with forceps and cute off the knee end. The 27G needle which contained MEM media supplemented with 20\% fetal bovine serum (FBS) (Cellgro Mediatech, USA) and $100 \mathrm{mg} / \mathrm{ml}$ for each ampicillin and 
streptomycin as culturing media should fit snugly into the bone cavity, then end of the femur was cut off as close to the end. The tip of the bone was inserted into a test tube $(15 \mathrm{ml})$ and aspirated and depressed the syringe plunger several times until all the bone marrow is flushed out of the femur and tibias. The marrow was dispersed to a suspension by pipetting the large marrow cores through pipetting. Finally the $10-\mathrm{mL}$ aliquots of the cell suspension were dispensed into $25-\mathrm{cm}^{2}$ tissue culture flasks and the cultures were maintained at $37^{\circ} \mathrm{C}$ in humidified $95 \%$ air and $5 \% \mathrm{CO}_{2}$ incubator.

\subsection{Culturing and Propagation of MSCs}

According to Freshney [28], cells where allowed to adhere overnight and non adherent cells were washed out with medium changes after $24 \mathrm{~h}$ on MEM media with $20 \%$ FBS. Then cultures were maintained, and the remaining non adherent cells was removed by exchanging of culture medium each 2 - 3 day until the cultures were get hold of developing colonies of adherent cells (about 5 - 7 days) to form monolayer's cells. After that cells were recovered (sub cultured) after getting monolayer cells using $0.25 \%$ trypsin-EDTA (US Biological, Massachusetts USA). The first passage (P1) cells began to proliferate and formed a monolayer of cells for the next 3 5 days. the culturing of P1 of MSCs were ready to used for immunophenotypic analysis.

\subsection{Immunophenotypic Analysis of MSCs}

The MSCs were re-cultured (P1) in 8-well tissue culture chamber slide (IWKA, Japan) in MEM media supplemented with 20\% FBS. The cells were allowed to developing a monolayer of adherent cells within 3 - 5 days, then the medium was aspirated and the multi-well plates washed two times with PBS, fixed with $4 \%$ paraformaldehyde (diluted in PBS) for 10 minutes, washed with PBS and leaved to dry, these slide were used in immunocytochemistry assay as triplicate. Four specific markers for immunocytochemistry analysis were used: CD90 (1:100; Mouse anti-human antibody, US biological, USA), CD105 (1:100; Mouse anti-human antibody, US biological, USA), and CD44 (1:100; Rat anti-mouse antibody, US biological, USA) as positive markers and CD34 (1:100; Goat anti-human antibody, Santa Cruz Biotechnology) as negative markers.

The fixed slides were incubated in a humidified chamber with $1 \%$ hydrogen peroxide $\left(\mathrm{H}_{2} \mathrm{O}_{2}\right)$ for 10 minutes, washed two to three times with PBS, incubated with $1.5 \%$ blocking serum for 30 - 40 minute at room temperature (the kit was ImmunoCruz mouse ABC Staining System from Santa Cruz Biotechnology, Europe). Then the ICC done according to the manufacture protocol with triplicate replication for each CDs marker. The slides were stained with DAP (provided in the kit) and Hematoxlin stain (SYRBIO, Syria) mounted with DPX (CDH, India) then were inspected by using light microscope and photographed by using digital camera.

\subsection{Neural Differentiation Induction of MSCs}

Subconfluent cultures of P1 MSCs were pretreated for $24 \mathrm{~h}$ in MEM media with 20\% FBS and $10 \mathrm{ng} / \mathrm{ml} \mathrm{bFGF}$ (US biological, USA) as preinduction media. Then neural differentiation (as post induction media) was induced with MEM media without FBS (serum free media), 2\% DMSO (Santa Cruz, USA), and $200 \mu$ M BHA (Santa Cruz Biotechnology, USA) as modified from Woodbury et al. [29]. Then cells were fixed for immunocytochemistry for MSCs and seven different time (25, 27, 29, 48, 96, and 144 h) for each NES, NF-L, and MAP-2 with triplicate replication for each marker. The cells were fixed for immunocytochemistry study (the kit from Immuno Cruz mouse ABC Staining System, Santa Cruz Biotechnology, Europe) at all these different times postinduction, and stained for NES (1:50; Mouse anti-rat, Santa Cruz Biotechnology, Europe), and NF-L (1:100; Mouse anti-porcine, US biological, USA) as immature neural cells markers, and for MAP-2 (1:50; Mouse anti-human, Santa Cruz Biotechnology) as mature neural markers, and the ICC assay was carried out as described above.

\subsection{RNA Isolation}

Total RNAs were collected using the absolutely RNA miniprep kit (Stratagen Aglient, Germany). Cells before (MSCs) and after differentiation (neural cells) from different exposure times (25, 27, 29, 48, 96, and $144 \mathrm{~h}$ ) were collected by trypsinization of adherent cells. The quality and quantity of total extracted RNA samples were then examined using minodrop UV-Vis. Spectrophotometer measurements (Quawell, Vietnam), and then the extracted RNAs were storage at $-80^{\circ} \mathrm{C}$ on deep freezer (Nüve, Turkey) until used. 


\subsection{Real Time-PCR}

The isolated RNAs reversed transcribed to produce double stranded cDNA via reverse transcriptase polymerase enzyme (KAPA SYBR FAST One-Step qRT-PCR Kit Universal, KAPA BIOSYSTEMS, South Africa, USA) to quantify expression of specific 3 genes nestin (forward: 5'-GCACT GGGAAG AGTAGAAGATG-3', length 22 and the reverse: 5'-GGAGTAG AGTCAGGGAGAGTTT-3', length 22) with fragment size 131bp, NF-L (forward: 5'-TGATGTCT GCTCGCTCTTTC-3', length 20 and the reverse: 5'-CTCAGCTTTCGTA GCCTCAAT-3', length 21) with fragment size 95 bp, MAP-2 (forward: 5'-CACAGGGCACCTAT TCAGATAC-3', length 22 and the reverse: 5'-CAGATACCTCCTCTGCTG TTTC-3', length 22) with fragment size 87 bp, GAPDH (forward: 5'-GGAGAGT GTTTCCTCGTCCC-3', length 20 and the reverse: 5'-TTTGC CGTGAGTGGAGTCAT-3', length 20) with fragment size 188 bp. These primers were optimized for use with SYBR green and normalization with housekeeping gene GAPDH with $50 \mathrm{ng} / \mu$ concentration. The Real Time-PCR done according to the manufacturer's protocol with annealing temperature $62^{\circ} \mathrm{C}$ and 40 cycle. All primers were designed in house with the National Center for Biotechnology Information (NCBI) Designer software (http://www.ncbi.nlm.nihgov/) and synthesized by BIO-Synthesis (Lewisville, TX, USA) for all 3 primers except GAPDH primer from Bio Corp (North America, USA). Once suitable reference genes (GAPDH) were identified, the mean CT values of the three candidate genes were calculated for each individual sample (as duplicate replication for each sample) and used to normalize expression levels using the $\Delta \Delta \mathrm{CT}$ method described previously [30]-[32].

\section{7. cDNA Electrophoresis}

All RNAs were running by gel electrophoresis method for MSCs and all different exposure time for each four primers, and with DNA Ladder (KAPA Express DNA Ladder Kit, KAPA Biosystems, USA) to show the quantity of genes expression studied. The preparations were done according to Maniatis and co-workers [33] and all reagents and marker were freshly prepared [1]. The gel afterward, removed from the tank and visualized by gel documentation system specialized with ethidium bromide/UV filter (SCIE-PLAS) and photographed.

\subsection{Statistical Analysis}

All ICC (as average percentage means) and Real Time-PCR data (as average means after finding the $\Delta \Delta C T$ values) was statistically analyzed using One Way ANOVA and LSD test in IBM SPSS Statistics Software (version 20) and the difference of means was considered significant at $\mathrm{p}<0.05$.

\section{Results}

\subsection{Culturing and Propagation of MSCs}

The MSCs from mouse bone marrow was cultured in tissue culture flasks in MEM supplemented with 20\% FBS. After $24 \mathrm{~h}$, only a few cells attached to the plastic culture flasks sparsely, and formed adherent cells while the non-adherent cells were discarded by the first medium change usually after 24 or $48 \mathrm{~h}$ (Figure 1(A)). The adherent cells began to proliferate, as soon as 2 - 3 days after cultivation numerous fibroblast like-cells could be observed, and gradually grow to form small individual colonies displaying fibroblast-like morphology with short and long processes as well as, a small round cells with a high nuclear to cytoplasmic ratio can also seen (Figure 1(B)). Mesenchymal stem cells are characterized by their ability to form colonies comprising spindle-shaped cells deriving from a single cell. The number of cellular colonies with different size has obviously increased.

Cells in large colonies were more densely distributed and showed a spindle like shape, as growth of cells continued, colonies gradually expanded in size with adjacent ones interconnected with each other. When the cells grow to $80 \%$ confluence (which observed through microscopic examination) after 5 - 6 days so they were ready to passaged (Figure 1(C)). Subculture done by through the media, treating with $0.25 \%$ trypsin-EDTA and cell suspension passed into new tissue culture flasks under the same conditions at a split ratio 1:2 for the first passage culture. The MSCs began to grow and formed colonies then expanded, and after few days from P1, a homogeneous layer of fibroblastoid-like cells occupied the whole plastic surface (Figure 1(D)). The cells can reseeded in same conditions for the second passage culture, and these adherent cells could be readily expanded in vitro by successive cycles of trypsinization, seeding and culture every 5 - 7 days without visible morphologic alteration. 

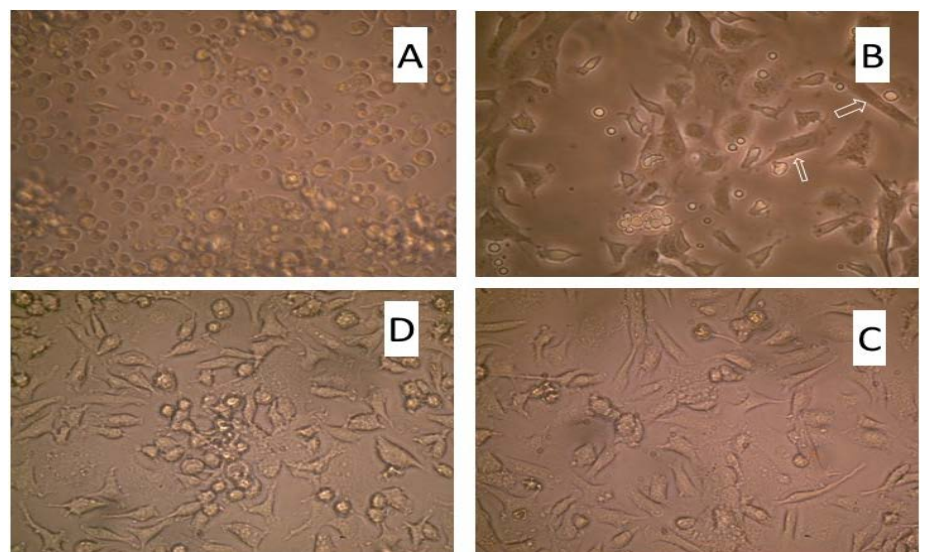

Figure 1. (A): Morphology characteristics of mouse MSCs cultured in MEM $+20 \%$ FBS after 24 h 20×. (B) After 72 h of culturing mouse MSCs in MEM $+20 \%$ FBS, note that some of cells adherent and began to elongated 20×. (C) After 5 - 6 days of culturing (monolayer cells), note that the colonies interconnected with each other and reaching a confluent stage $20 \times$. (D): MSCs morphology after the first passage $20 \times$.

\subsection{Immunophenotypic Characterization of MSCs}

The Immunophenotypic characterization of the cultured MSCs expanded adherent cells revealed that the cells were stained with blue color and were negative for CD34 (Figure 2(G)). Cells with brown color were positive for each of CD44, CD90 and CD105 (Figures 2(A)-(F)).

These results demonstrated that the cells turned out to be positive for CD105, CD90 and CD44, which take the brown color (from DAP stain) indicating that they retain the phenotype of MSCs. And the results showed that MSCs were negative for CD34 which take the blue color (from Hematoxlin stain), which indicating that these cells are not from hematopoietic origin but they were MSCs.

\subsection{Neural Differentiation Induction of MSCs}

In the preinduction media (for $24 \mathrm{~h}$ exposure), the MSCs was showed to be more elongated (Figures 3(A)-(G)) without increased the protein expression (Immunocytochemistry assay ICC) for each NES, NF-L, and MAP-2 (Figure 4(A) and Figure 4(B), Figures 4(A)-(G) for each marker). After exposure to BHA for different times as postinduction differentiation media, the MSCs started to be more elongated and it increased in cells size, then finally it formed cells branches as the neuron cells with the increased of the NES and NF-L protein expression with significant difference level at $\mathrm{p}<0.05$ with the higher proteins expressions in the $144 \mathrm{~h}$ compared with the control (undifferentiating MSCs). Whereas the MAP-2 proteins showed the less expression levels compared with NES and NF-L with significant difference between different time at level at $\mathrm{p}<0.05$ compared with control (undifferentiating MSCs) (as showed in Figure 5). These results indicated the activity of BHA in the neurogenesis stages of MSCs toward the neural differentiation cells.

\subsection{Real Time-PCR}

The results of RealTime-PCR revealed that the expression of NES gene (as immature differentiation gene) was considerable in the BHA treated cells and gave rise to a detectable band, which increased with exposure time started with 29, 48, 96 and $144 \mathrm{~h}$ While no gene expression was observed in the control cells (undifferentiated MSCs). In the first hours 25 and $27 \mathrm{~h}$, the NF-L gene was showed higher expression levels after treated and give rise to detectable band (as showed in nestin gene) which increased with exposure time started from $29-144 \mathrm{~h}$, compared with the MAP-2 gene (as post maturation gene) which showed low expression levels in all time exposure after treatment compared with control (MSCs). Also the results showed the stability of gene expression levels of GAPDH gene (as showed in Figure 6). These results indicated that the immature neural markers NES and NF-L were started to increase their gene expression through the neurogenesis stages of MSCs toward neural cell differentiation compared with low gene expression levels in the mature neural marker MAP-2 gene which indicated the affectivity of BHA towards neural cells differentiation. 

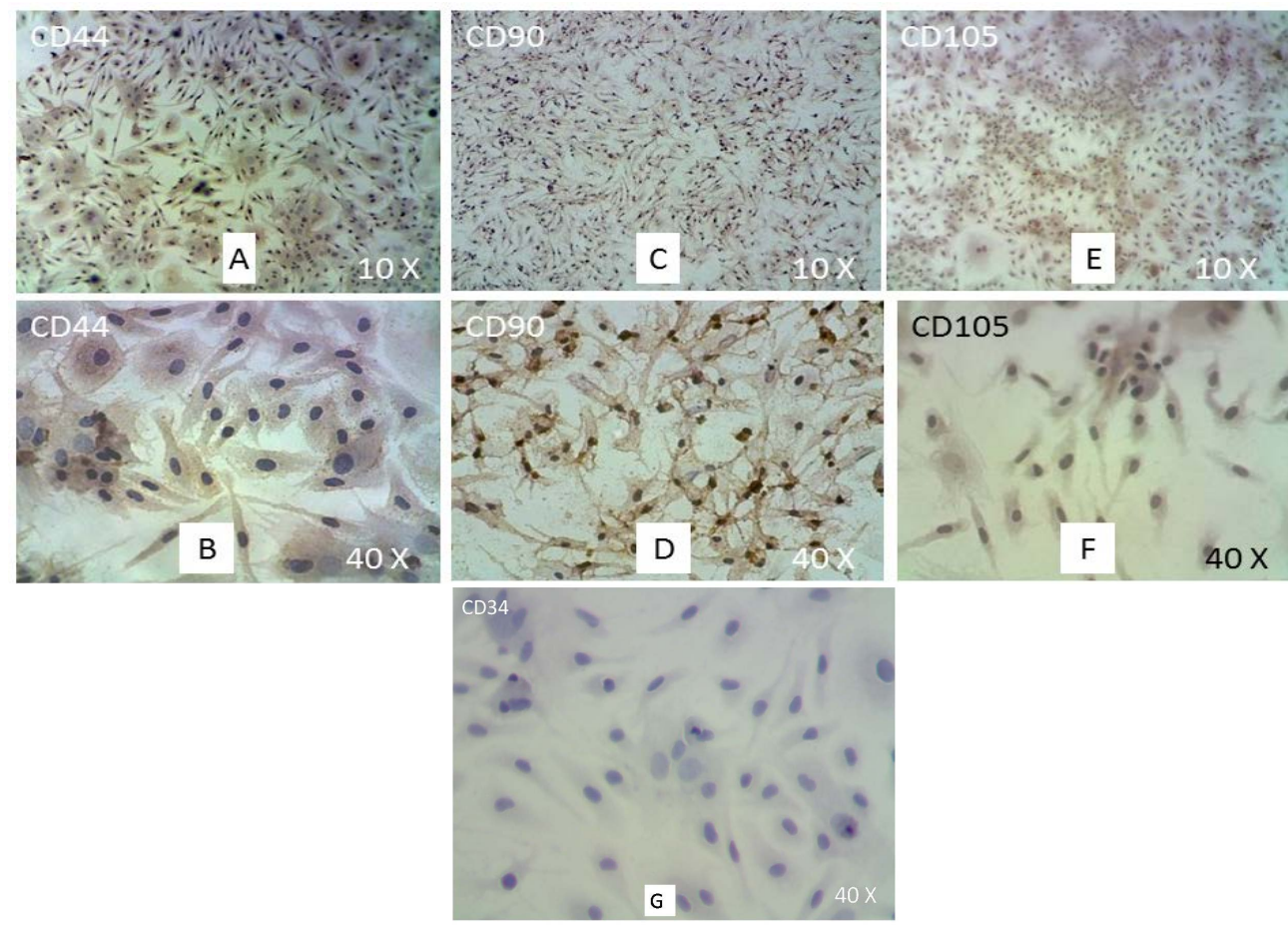

Figure 2. Immunophenotypic analysis of MSCs at the first passage revealed under light microscope show that the MSCs were positive cells which stained with brown color. (A \& B): CD44, (C \& D): CD90, (E \& F) CD105, note that all CDs showed with 10× and 40× respectively. (G): Immunophenotypic analysis of MSCs at the first passage showing that the MSCs were negative for CD34 by cell stained only with blue color $40 \times$.
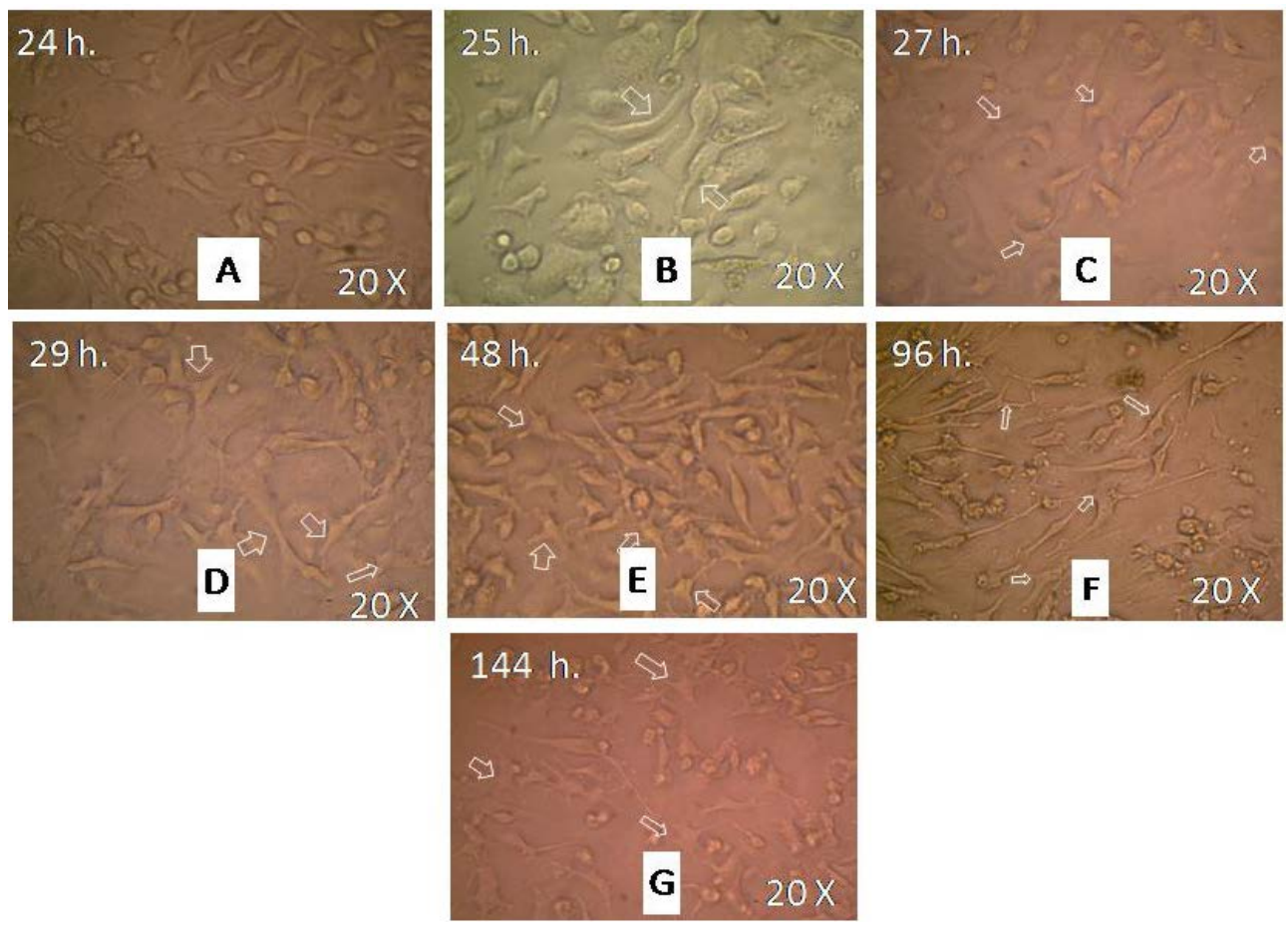

Figure 3. MSCs after induced differentiation by BHA, which showed the elongation of cells and branched form towards neural cells as revealed under inverted microscope, all figure showed in 20×. the Figures 3(A)-(G) were presented $(24$ - $144 \mathrm{~h})$ exposure time to differentiation media. 

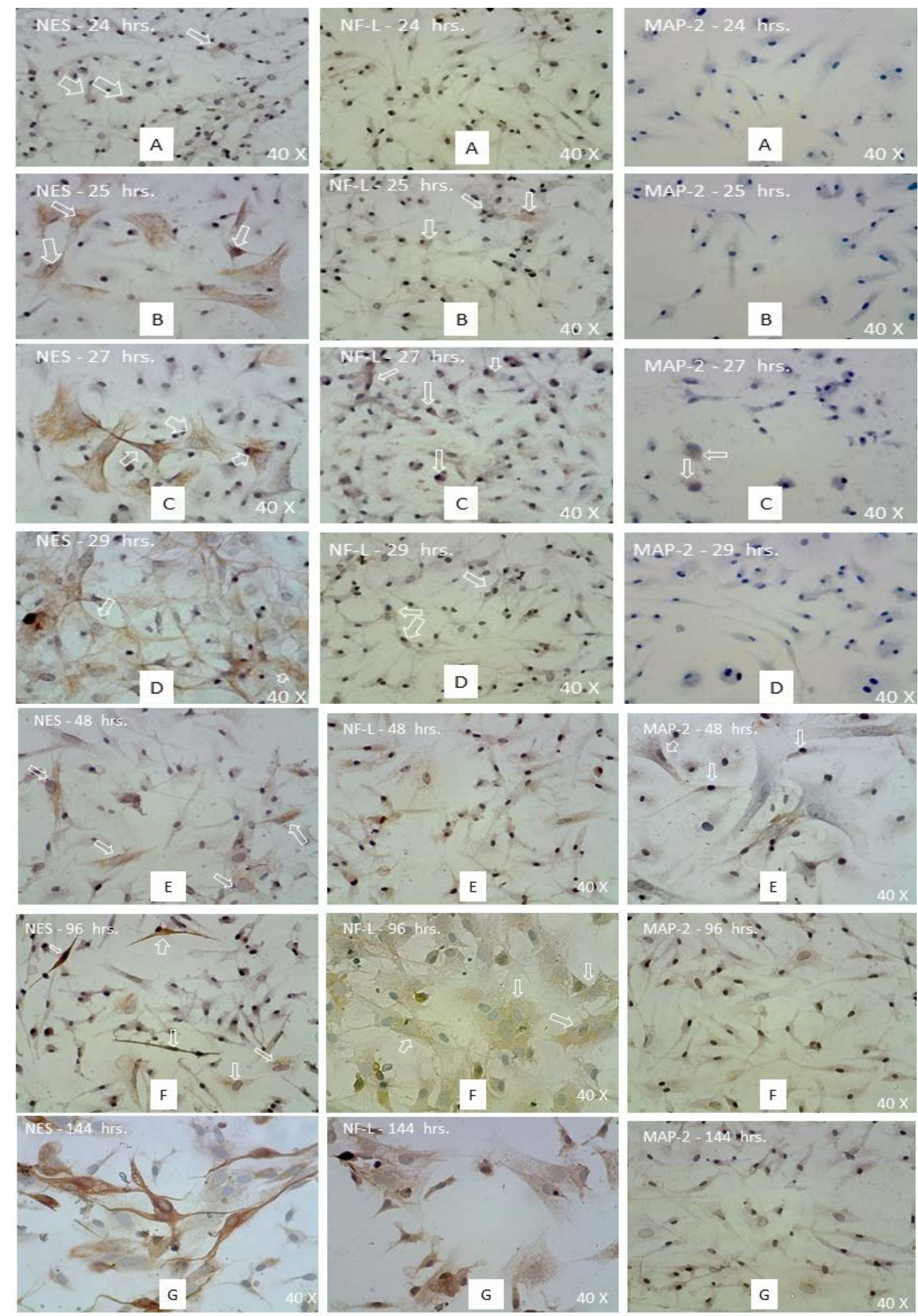

Figure 4. (A, B): Immunocytochemistry detection of neural progenitor markers after MSCs differentiation induction by BHA. The figure showed increased expression of NES, NF-L proteins through the different exposure times as presented by increase the intensity of staining compared with no increasing of MAP-2 protein as revealed under Light microscope, all figure showed in 40×, the Figures 4(A)-(D) were for (24 - $29 \mathrm{~h}$ ) and figures (E-G) were for ( 48 - $144 \mathrm{~h}$ ) exposure times. 


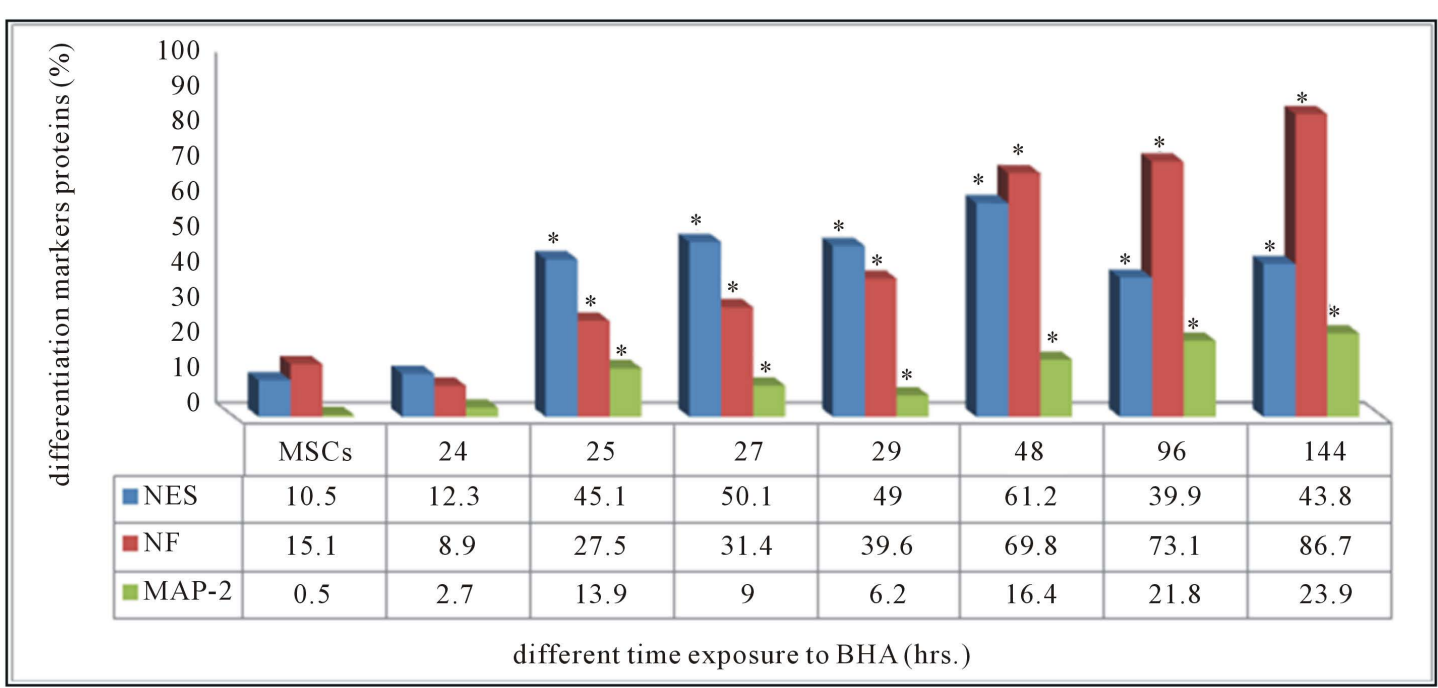

Figure 5. The proteins expression levels of Immunocytochemistry assay for NES, NF-L, and MAP-2 antibodies after differentiation by BHA. *Refer to significant effect at $\mathrm{p}<0.05$.
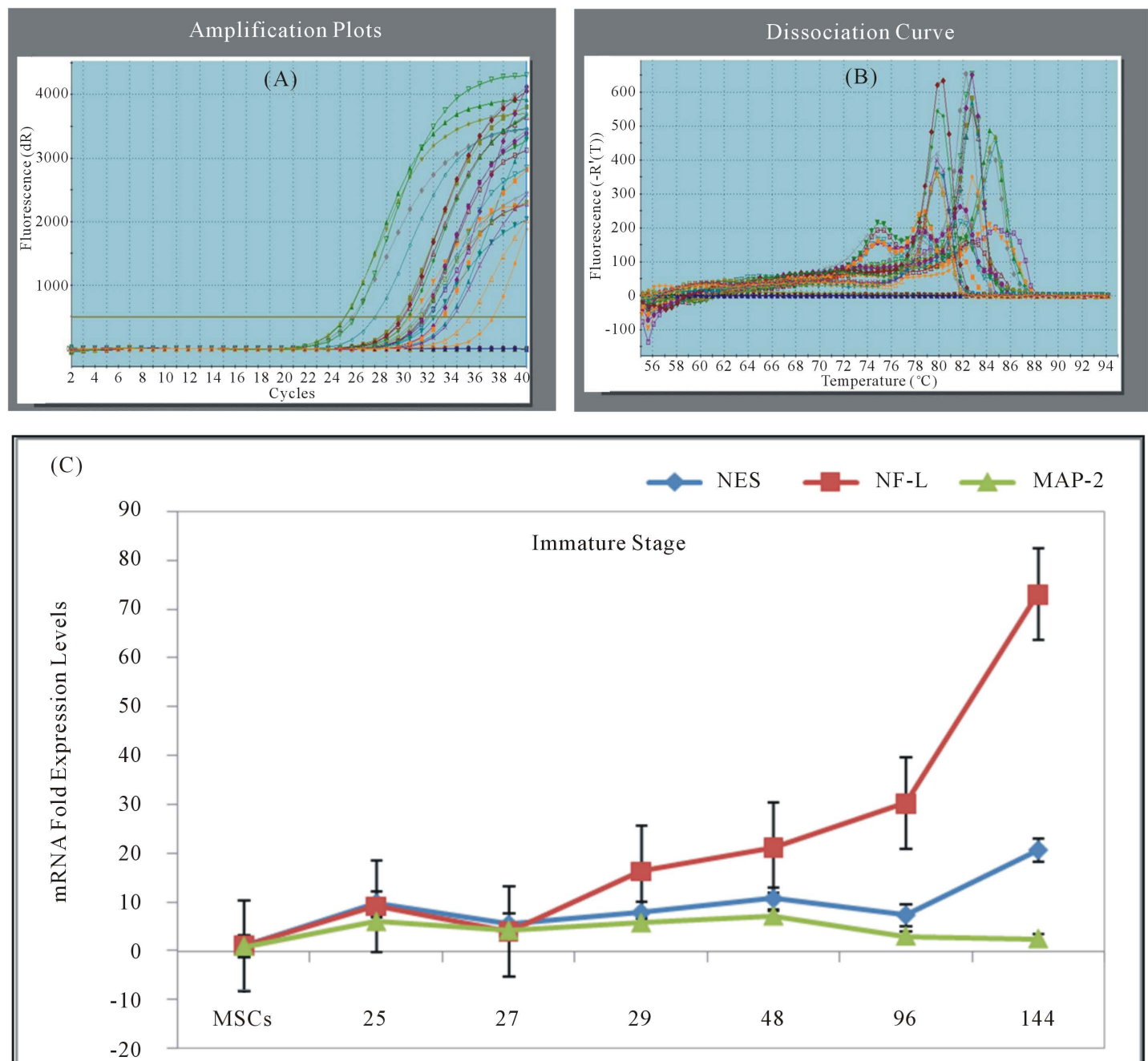

Different Time Exposure to BHA (hrs.) 

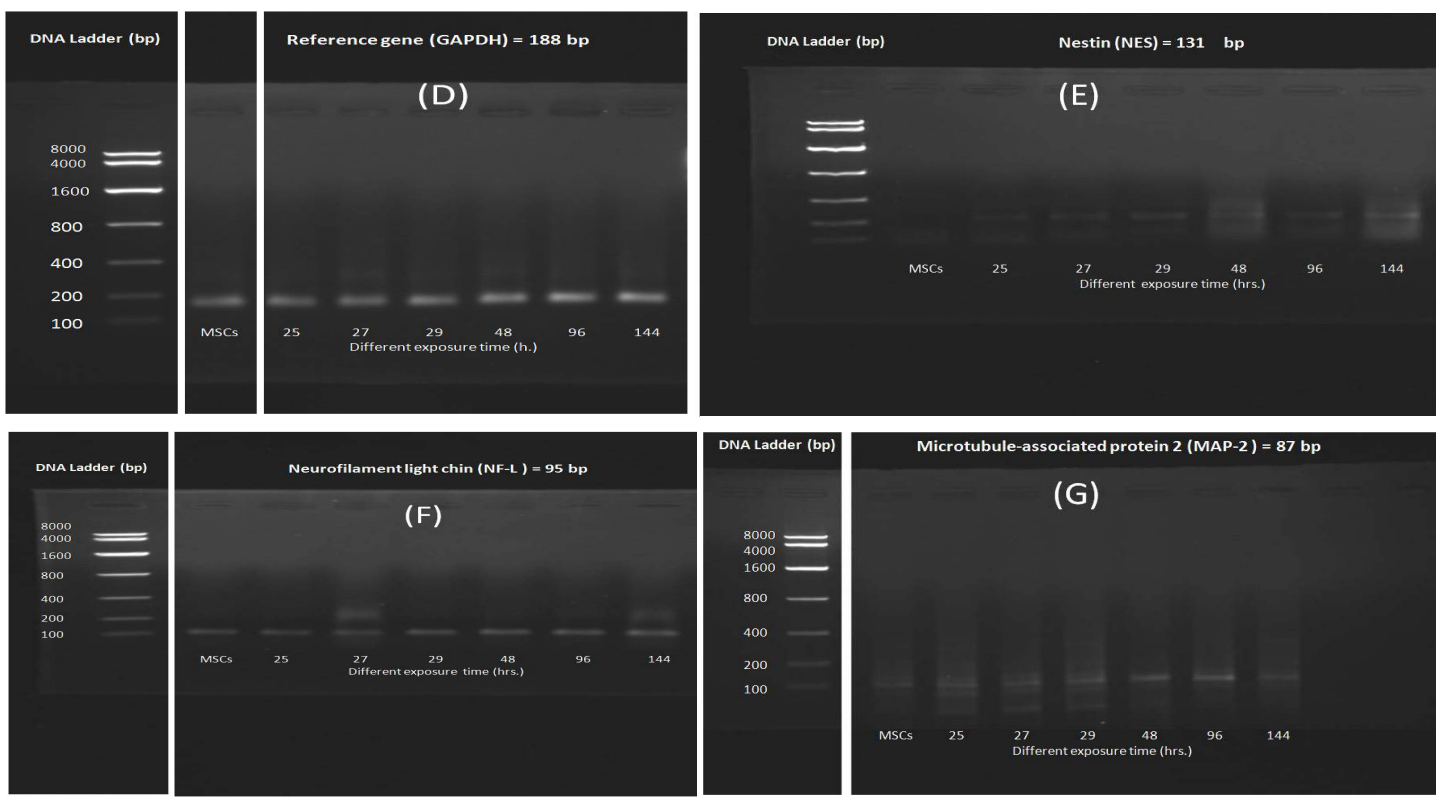

Figure 6. mRNA expression levels of Real Time-PCR analysis of NES, NF-L, and MAP-2 genes in mouse MSCs treated with BHA, there was a high expression levels with significant difference between each NES and NF-L primer compared with control (MSCs) $(\mathrm{p}<0.05)$ for different exposure times, and low expression levels on MAP-2 with significant difference for different exposure times $(\mathrm{p}>0.05)$. Note that all these 3 primers was normalized with GAPDH gene (A): Amplification Plot of all primers, (B): Dissociation curve of all primers, (C) Results of Real Time-PCR, note that these data represents the $\triangle \mathrm{CT}$ of mean \pm SEM. (D-G): Gel electrophoresis analysis of Real Time-PCR of NES, NF-L, and MAP-2 genes respectively.

\section{Discussion}

This study showed that after exposure to BHA started from 1 - 5 day can lead to morphological changes in mouse bone marrow MSCs featuring a neuron-like morphology such as rounded cell bodies and long branching processes along with the growth of cone-like terminal structures. Many studies demonstrated the differentiation of human and mice MSCs to neuron-like cells following induction with BME, DMSO and BHA [34]-[40], which exhibited a neuron-like morphology for few hours after induction which is due to a breakdown of the actin cytoskeleton and a retraction of the cell edge [40]. Since BHA also contains the sulfhydryl group, it may be deduced that the neuron-like morphology adopted by the exposed mouse MSCs has the same mechanism and could be due to the disruption of F-actin and cytoskeleton reorganization.

In the present study, the differentiation process of mouse bone marrow MSCs was followed by monitoring the mRNA expression (protein expression) of nestin and NF-L genes as the two important neuron-specific markers (REF). The expression of nestin and NF-L genes increased in MSCs started from 5 hours of exposure to BHA (29 h treated cells), which could be a sign of differentiation in the treated cells.

Other investigations have studied the expression of a wide range of mRNAs and proteins, including those normally reported in terminally differentiated neural cells [41]-[43]. Then many studies demonstrated that neural cells derived from bone marrow MSCs expressed mRNA species encoding many type of genes such as $\beta$-tubulin III (an early neural marker), nestin, neurofilaments (NFs), glial fibrillary acidic protein (GFAP) (as neural cell markers), and the specific neural markers such as choline acetyltransferase (ChAT), and MAP-2 and many other markers [22] [42] [44]-[46].

The results showed that nestin protein existed in high levels from first $24 \mathrm{~h}$ Until the end of the differentiation time at $144 \mathrm{~h}$, Nestin expression is transient and does not persist into adulthood and nestin become down regulated and replaced by tissue specific intermediate filament proteins [34]. In our results neurofilament protein expression start to increase after $48 \mathrm{~h}$ but not replaced the nestin expression completely even when its expression passed nestin levels where the nestin still existed in good levels. Lalonde et al. [46] showed that neurofilament is necessary to function primarily to provide structural support for the axon and to regulate axon diameter. The maturation marker Map-2 expression was low during the duration of differentiation period, which prove that 
cells are still progenitors and can be redirected into specific neurons by further treatments [36] [47] [48].

\section{Conclusion}

The current work spotted the light on the specific expression timing for the differentiation markers (NES, NF-L and Map-2) to help identify the progenitor status of the induced neurogenesis of the mouse bone marrow mesenchymal stem cells and the possibility of using them for further maturation into highly specialized specific functional neuron of many types of neurons present in the nervous system.

\section{Acknowledgements}

This work was supported from the Iraqi Center of Cancer and Medical Genetic Research (ICCMGR) and Biology Department/College of Science for Women/University of Baghdad.

\section{References}

[1] Nöth, U., Osyczka, A.M., Tuli, R., et al. (2002) Multilineage Mesenchymal Differentiation Potential of Human Trabecular Bone-Derived Cells. Journal of Orthopaedic Research, 20, 1060-1069. http://dx.doi.org/10.1016/S0736-0266(02)00018-9

[2] Tuan, R.S., Boland, G. and Tuli, R. (2003) Adult Mesenchymal Stem Cells and Cell-Based Tissue Engineering. Arthritis Research and Therapy, 5, 32-45. http://dx.doi.org/10.1186/ar614

[3] Pittenger, M.F., Mackay, A.M. and Beck, S.C. (1999) Multilineage Potential of Adult Human Mesenchymal Stem Cells. Science, 284, 143-147. http://dx.doi.org/10.1126/science.284.5411.143

[4] Al-Shammari, A.M., Al-Joboury, A.A. and Yaseen, N.Y. (2012) Isolation and Culture of Neuronal Stem Cells Which Directed into Purkinje Cells to Be Used for Brain Damage and Epilepsy Treatment in Mice. Molecular Therapy, 20, 201-202.

[5] Lee, K.D., Kuo, T. and Whang-Peng J. (2004) In Vitro Hepatic Differentiation of Human Mesenchymal Stem Cells. Hepatology, 40, 1275-1284. http://dx.doi.org/10.1002/hep.20469

[6] Alshammari, A.M., Salman, M.I. and Umran, M.A. (2015) Chondrogenesis Markers "COL1A1, COL2A1 and CRTAC1” Expression during Differentiation of Mice Bone Marrow Mesenchymal Stem Cells. International Journal of Research Studies in Biosciences, 3, 45-56.

[7] Moon, H.E., Seung, H.Y., Yong, S.H., et al. (2013) Mitochondrial Dysfunction of Immortalized Human Adipose TissueDerived Mesenchymal Stromal Cells from Patients with Parkinson's Disease. Experimental Neurobiology, 22, $283-300$. http://dx.doi.org/10.5607/en.2013.22.4.283

[8] Sadan, O., Shemesh, N., Barzilay, R., et al. (2012) Mesenchymal Stem Cells Induced to Secrete Neurotrophic Factors Attenuate Quinolinic Acid Toxicity: A Potential Therapy for Huntington’s Disease. Experimental Neurology, 234, $417-$ 427. http://dx.doi.org/10.1016/j.expneurol.2011.12.045

[9] Mazzini, L., Mareschi, K., Ferrero, I., et al. (2012) Mesenchymal Stromal Cell Transplantation in Amyotrophic Lateral Sclerosis: A Long-Term Safety Study. Cytotherapy, 14, 56-60. http://dx.doi.org/10.3109/14653249.2011.613929

[10] Karina, O.G., Felipe, L.M., Priscila, K.M., et al. (2014) Therapeutic Effects of the Transplantation of VEGF over Expressing Bone Marrow Mesenchymal Stem Cells in the Hippocampus of Murine Model of Alzheimer's Disease. Frontiers in Aging Neuroscience, 6, 30.

[11] Sagara, J. and Makino, N. (2008) Glutathione Induces Neuronal Differentiation in Rat Bone Marrow Stromal Cells. Neurochemical Research, 33, 16-21. http://dx.doi.org/10.1007/s11064-007-9400-3

[12] Abouelfetouh, A., Kondoh, T., Ehara, K. and Kohmura, E. (2004) Morphological Differentiation of Bone Marrow Stromal Cells into Neuron-Like Cells after Co-Culture with Hippocampal Slice. Brain Research, 1029, 114-119. http://dx.doi.org/10.1016/j.brainres.2004.07.092

[13] Qian, L. and Saltzman, W.M. (2004) Improving the Expansion and Neuronal Differentiation of Mesenchymal Stem Cells through Culture Surface Modification. Biomaterials, 25, 1331-1337. http://dx.doi.org/10.1016/j.biomaterials.2003.08.013

[14] Lee, J.H., Yu, H.-S., Lee, G.-S., Ji, A., Hyun, J.K. and Kim, H.-W. (2011) Collagen Gel Three-Dimensional Matrices Combined with Adhesive Proteins Stimulate Neuronal Differentiation of Mesenchymal Stem Cells. Journal of the Royal Society Interface, 8, 998-1010. http://dx.doi.org/10.1098/rsif.2010.0613

[15] Nichols, J.E., Jean, A.N., Douglas, D.W., et al. (2013) Neurogenic and Neuro-Protective Potential of a Novel Subpopulation of Peripheral Blood-Derived CD133+ ABCG2+CXCR4+ Mesenchymal Stem Cells: Development of Autologous Cell Based Therapeutics for Traumatic Brain Injury. Stem Cell Research \& Therapy, 4, 3. 
http://dx.doi.org/10.1186/scrt151

[16] Feng, Z. and Gao, F. (2012) Stem Cell Challenges in the Treatment of Neurodegenerative Disease. CNS Neuroscience \& Therapeutics, 18, 142-148. http://dx.doi.org/10.1111/j.1755-5949.2011.00239.x

[17] Huang, H., Lin, C. and Paul, S. (2010) Cell Therapy from Bench to Bedside Translation in CNS Neurorestoratology Era. Cell Medicine, 1, 15-46. http://dx.doi.org/10.3727/215517910X516673

[18] Zhao, L., Lin, Y.D., Ma, J., Sun, Y.Y., Zeng, S.J., Zhang, X.W. and Zuo, M.X. (2007) Culture and Neural Differentiation of Rat Bone Marrow Mesenchymal Stem Cells in Vitro. Cell Biology International, 31, 916-923. http://dx.doi.org/10.1016/j.cellbi.2007.02.006

[19] Cui, P., He, X.H., Pu, Y.B., Zhang, W.X., Zhang, P., Li, C.L., Guan, W.J., Li, X.C. and Ma, Y.H. (2014) Biological Characterization and Pluripotent Identification of Sheep Dermis-Derived Mesenchymal Stem/ Progenitor Cells. BioMed Research International, 2014, Article ID: 786234. http://dx.doi.org/10.1155/2014/786234

[20] Zhao, G.G., Ji, H.J., Wang, S.H., Gu, B., Song, X.L., Zhang, J.R., Liu, Y.K., Chen, L.B. and Zhang, M. (2014) Cell Surface Proteomics Analysis Indicates a Neural Lineage Bias of Rat Bone Marrow Mesenchymal Stromal Cells. BioMed Research International, 2014, Article ID: 479269. http://dx.doi.org/10.1155/2014/479269

[21] Mehranjani, S.M. and Chian, F.M. (2014) Cysteine: A Novel Neural Inducer for Rat Bone Marrow Mesenchymal Stem Cells. Cell Journal, 16, 195-202.

[22] Kim, E.Y., Lee, K.-B., Yu, J., et al. (2014) Neuronal Cell Differentiation of Mesenchymal Stem Cells Originating from Canine Amniotic Fluid. Human Cell, 27, 51-58. http://dx.doi.org/10.1007/s13577-013-0080-9

[23] Birbrair, A., Wang, Z.M., Messi, M.L., Enikolopov, G.N. and Delbono, O. (2011) Nestin-GFP Transgene Reveals Neural Precursor Cells in Adult Skeletal Muscle. PLOS ONE, 6, e16816. http://dx.doi.org/10.1371/journal.pone.0016816

[24] Leonard, D.B., Gorham, J.D., Cole, P., Greene, L.A. and Ziff, E.B. (1988) A Nerve Growth Factor-Regulated Messenger RNA Encodes a New Intermediate Filament Protein. The Journal of Cell Biology, 106, 181-193. http://dx.doi.org/10.1083/jcb.106.1.181

[25] Wieske, L., Witteveen, E., Petzold, A., Verhamme, C., Schultz, M.J., van Schaik, I.N. and Horn, J. (2014) Neurofilaments as a Plasma Biomarker for ICU-Acquired Weakness: An Observational Pilot Study. Critical Care, 18, R18. http://dx.doi.org/10.1186/cc13699

[26] Caceres, A., Banker, G.A. and Binder, L. (1986) Immunocytochemical Localization of Tubulin and Microtubule-Associated Protein 2 during the Development of Hippocampal Neurons in Culture. The Journal of Neuroscience, 6, 714-722.

[27] Fischer, I., Shea, T.B., Sapirstein, V.S. and Kosik, K.S. (1986) Expression and Distribution of Microtubule-Associated Protein 2 (MAP2) in Neuroblastoma and Primary Neuronal Cells. Developmental Brain Research, 25, 99-109. http://dx.doi.org/10.1016/0165-3806(86)90156-2

[28] Freshney, R.I. (2005) Culture of Animal Cells: A Manual for Basic Technique. Fifth Edition, Wiley, New York. http://dx.doi.org/10.1002/9780471747598

[29] Woodbury, D., Schwarz, E.J., Prockop, D.J. and Black, I.B. (2000) Adult Rat and Human Bone Marrow Stromal Cells Differentiate into Neurons. Journal of Neuroscience Research, 61, 364-367. http://dx.doi.org/10.1002/1097-4547(20000815)61:4<364::AID-JNR2>3.0.CO;2-C

[30] Vandesompele, J., De Preter, K., Pattyn, F., Poppe, B., Van Roy, N., De Paepe, A. and Speleman, F. (2002) Accurate Normalization of Real-Time Quantitative RT-PCR Data by Geometric Averaging of Multiple Internal Control Genes. Genome biology, 3, RESEARCH0034.

[31] Livak, K.J. and Schmittgen, T.D. (2001) Analysis of Relative Gene Expression Data Using Real-Time Quantitative PCR and the $2^{-\triangle \Delta C T}$ Method. Methods, 25, 402-408. http://dx.doi.org/10.1006/meth.2001.1262

[32] Schmittgen, T.D., Livak, K.J. (2008) Analyzing Real-Time PCR Data by the Comparative $\mathrm{C}_{\mathrm{T}}$ Method. Nature Protocols, 3, 1101-1108. http://dx.doi.org/10.1038/nprot.2008.73

[33] Green, M.R. and Sambrook J. (2012) Analysis of DNA. In: Molecular Cloning a Laboratory Manual, 4nd Edition, Volume 1, Cold Spring Harbor Laboratory Press, New York, 94-99.

[34] Michalczyk, K. and Ziman, M. (2005) Nestin Structure and Predicted Function in Cellular Cytoskeletal Organisation. Histology and Histopathology, 20, 665-671.

[35] Woodbury, D., Reynolds, K. and Black, I.B. (2002) Adult Bone Marrow Stromal Stem Cells Express Germ Line, Ectodermal, Endodermal, and Mesodermal Genes Prior to Neurogenesis. Journal of Neuroscience Research, 69, 908-917. http://dx.doi.org/10.1002/jnr.10365

[36] Harvey, B.S. (2013) Clinical Neuropathology Practice Guide 5-2013: Markers of Neuronal Maturation. Clinical Neuropathology, 32, 340-369. http://dx.doi.org/10.5414/NP300638 
[37] Delcroix, G.J.-R., Jacquart, M., Lemaire, L., Sindji, L., Franconi, F., Le Jeune, J.-J. and Montero-Menei, C.N. (2009) Mesenchymal and Neural Stem Cells Labeled with HEDP-Coated SPIO Nanoparticles: In Vitro Characterization and Migration Potential in Rat Brain. Brain Research, 1255, 18-31. http://dx.doi.org/10.1016/j.brainres.2008.12.013

[38] Sanchez-Ramos, J., Song, S., Cardozo-Pelaez, F., et al. (2000) Adult Bone Marrow Stromal Cells Differentiate into Neural Cells in Vitro. Experimental Neurology, 164, 247-256. http://dx.doi.org/10.1006/exnr.2000.7389

[39] Zhang, H.B., Huang, Z.Y., Xu, Y.M. and Zhang, S.M. (2006) Differentiation and Neurological Benefit of the Mesenchymal Stem Cells Transplanted into the Rat Brain Following Intracerebral Hemorrhage. Neurological Research, 28, 104-112. http://dx.doi.org/10.1179/016164106X91960

[40] Kim, B.J., Seo, J.H., Bubien, J.K. and Oh, Y.S. (2002) Differentiation of Adult Bone Marrow Stem Cells into Neuroprogenitor Cells in Vitro. Neuroreport, 13, 1185-1188. http://dx.doi.org/10.1097/00001756-200207020-00023

[41] Hung, S.C., Chen, N.J., Hsieh, S.L., Li, H., Ma, H.-L. and Lo, W.-H. (2002) Isolation and Characterization of Size-Sieved Stem Cells from Human Bone Marrow. Stem Cells, 20, 249-258. http://dx.doi.org/10.1634/stemcells.20-3-249

[42] Iida, K. and Nishimura, I. (2002) Gene Expression Profiling by DNA Microarray Technology. Critical Reviews in Oral Biology \& Medicine, 13, 35-50. http://dx.doi.org/10.1177/154411130201300105

[43] Jiang, Y., Jahagirdar, B.N., Reinhardt, R.L., et al. (2002) Pluripotency of Mesenchymal Stem Cells Derived from Adult Marrow. Nature, 418, 41-49. http://dx.doi.org/10.1038/nature00870

[44] Egusa, H., Schweizer, F.E., Wang, C.C., Matsuka, Y. and Nishimura, I. (2005) Neuronal Differentiation of Bone Marrow-Derived Stromal Stem Cells Involves Suppression of Discordant Phenotypes through Gene Silencing. The Journal of Biological Chemistry, 280, 23691-23697. http://dx.doi.org/10.1074/jbc.M413796200

[45] Darabi, S., Tiraihi, T., Delshad, A. and Sadeghizadeh, M. (2013) A New Multistep Induction Protocol for the Transdifferentiation of Bone Marrow Stromal Stem Cells into GABAergic Neuron-Like Cells. Iranian Biomedical Journal, 17, 8-14.

[46] Lalonde, R. and Strazielle, C. (2003) Neurobehavioral Characteristics of Mice with Modified Intermediate Filament Genes. Reviews in the Neurosciences, 14, 369-385. http://dx.doi.org/10.1515/revneuro.2003.14.4.369

[47] Shafit-Zagarado, B., Rockwood, J., Davies, P., Kress, Y. and Lee, S.C. (2000) Novel Microtubule-Associated Protein-2 Isoform Is Expressed Early in Human Oligodendrocyte Maturation. Glia, 29, 233-245. http://dx.doi.org/10.1002/(SICI)1098-1136(20000201)29:3<233::AID-GLIA5>3.0.CO;2-U

[48] Mohammad-Gharibani, P., Tiraihi, T. and Arabkheradmand, J. (2009) In Vitro Transdifferentiation of Bone Marrow Stromal Cells into GABAergic-Like Neurons. Iranian Biomedical Journal, 13, 137-143. 